New York: Teachers College Press.

Connelly, F. M., \& Clandinin, D. J. (1987). Narrative inquiry: Storied experience. In E. Short (Ed.), Forms of curriculum inquiry (pp. 121 - 152). New York: State University of New York Press.

Germano, W. (2005). From dissertation to book. University of Chicago Press. Chicago.

Heap, J. (2005). Faculty Board document handout. September 21, 2005. Brock University.

Krathwohl, D.R., Bloom, B.S., and Masia, B.B. (1964). Taxonomy of educational objectives: Handbook II: Affective domain. New York: David McKay Co.

Neumann, A. (2006). Professing passion: Emotion in the scholarship of professors at research universities. American educational research journal. Vol. 43, no.3, pp. 381-424.

Noddings, N. (1992). The challenge to care in schools: An alternative approach to education. New York: Teachers College Press.

Palmer, P. (1998). The courage to teach: Exploring the inner landscape of a teacher's life. San Francisco: JosseyBass.

Sergiovanni, T.J. (2005). Strengthening the heartbeat: Leading and learning together in schools. San Francisco: Jossey-Bass.

Tjuer, B.A. (1994). Successful publishing in scholarly journals. Thousand Oaks, California.

Whicker, M.L., Kronenfeld, J.J., Strickland, R.A. (1993). Getting tenure. Sage Publications, Thousand Oaks, California

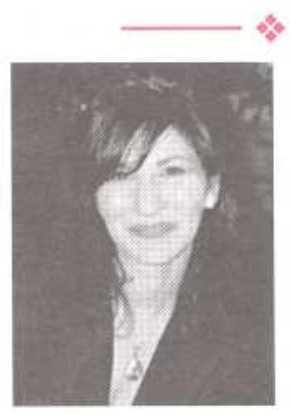

Darlene Ciuffetelli Parker has her $\mathrm{PhD}$ in Education and Curriculum and is a professor at Brock University. She has had extensive experience as a former teacher, literacy consultant and school administrator. Her research and writing stems from adults' and students' personal narratives of what it means to be literate and how multiple languages affect our place in society, school and family.

\title{
Managing Stress through Music Intervention: An Interview with
}

\section{Adrienne Pringle}

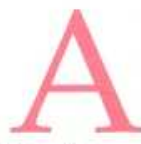
drienne Pringle is an ac complished vocalist and instrumentalist. She is a highly qualified Music Therapist who provides care and support to palliative care patients at Credit Valley Hospital, Mississauga, Ontario, Canada, but has also taugh music therapy courses, and supervises students at Wilfrid Laurier University, works in schools and with individuals at home and private practice. I have had the privilege to observe and witness first hand her efforts on behalf of patients and co workers. Her impact is nothing short of outstanding and serves as a reminder of the power of the gift that care givers provide to those who are in need spans across all professions. Her insight about how music therapy can be helpful in alleviating stress reveals much about this very special professional skill.

Chodzinski: Please describe for our readers the qualifications and roles of a music therapist.

Pringle: A music therapist is an accomplished musician who has received specialized training in music, psychology and the clinical use of music in therapy. The music therapist has graduated from an honours bachelor of music therapy program or a master's degree in music therapy at an accredited university. Upon completion of the four-year music therapy degree, the music therapist must then complete a one thousand hour internship under the supervision of an accredited music therapist. After the internship is completed, the music therapy intern submits a file of specific documentation to the $\mathrm{Ca}$ nadian Association of Music Therapy (CAMT) to be reviewed by the accreditation board. If the accreditation file meets the standards of the CAMT, the music therapist is granted the status of music therapist accredited (MTA). The field of music therapy is regulated both federally by the Canadian Association of Music Therapy (CAMT), and provincially (in Ontario) by the Music Therapy Association of Ontario (MTAO). As a musician, the music therapist uses musical elements such as harmony, melody, rhythm, and form as tools to meet the goals that are predetermined for the client. As a therapist, the music therapist recognizes the ability of music to affect behaviour, and adjusts the musical experiences of singing, moving, playing instruments, improvising, composing and listening in order for the client to receive the maximum benefit from the session.

Chodzinski: This issue is about stress in school communities. Please explain for our readers what music therapy is and how music therapists such as your self might assist to teachers and administrators, students and parents in schools.

Pringle: Pringle: Music therapy is the skillful use of music and musical elements by an accredited music 
therapist to promote, maintain, and restore mental, physical, emotional, and spiritual health. Music has nonverbal, creative, structural, and emotional qualities. These are used in the therapeutic relationship to facilitate contact, interaction, self-awareness, learning, self-expression, communication, and personal development. (CAMT, 1994)

Music therapy is wholly client centered. Before beginning a course of treatment, the music therapist assesses each client to gain insight into five areas of functioning (physical, cognitive, social, emotional, and musical). The music therapist then sets nonmusical goals and objectives based on the needs of the client. A treatment plan is devised to meet these goals. After each session the music therapist evaluates the client's progress in order to make any necessary changes and to provide the client with the highest quality of treatment. Since music therapy is clientcentered, it is also important for the music therapist to be in contact with other members of the client's treatment team. This ensures that the music therapist is able to be involved in the communication of the needs and successes of the client, leading to improved overall care.

Music therapy can be done individually or in a group setting. In order for the clients to best benefit from music therapy, it is recommended that there be no more than six clients in a group.

Chodzinski : Music therapy is a unique intervention that provides patients and clients with opportunities to respond and express themselves through music. How so?

Pringle: Music therapy is unique due to the multifaceted qualities that are naturally found in music. Music is universal. It is very difficult not to respond to music. Every person can relate to music in some way or another. This creates a common bond between people. Music therapists use this bond as a starting point to develop trust with clients, which leads to successful therapy. Music is also non-threatening. It is often easier for clients to express their feelings with music than without it. Adding music gives the clients an opportunity to look at their own feelings objectively and thus makes it easier for them to engage in effective problem solving. Music is important for children and teens with cognitive challenges -it can be used as an effective tool to trigger memory or structure activities of daily living. Music making is a social activity. This is especially important for the adolescent client, as peers and relationships are the focus of these formative years. Many social gatherings are based around listening, playing, or dancing to music. Music can effectively break down the barriers between those that are different and those that are accepted members of a large group. Since music is nonverbal it may be used to transcend the communication barrier that exists with those young people with receptive and/or expressive language disorders. Thoughts, moods, and feelings can all be expressed in a non-verbal medium. Music also offers an opportunity for adolescents to reveal their emotional life and explore their creativity through song writing and improvisation. In this way, individuals are allowed the opportunity to assert their musical self as a contributing member of the group, as well as assert their in- dependence as individuals. Another important aspect of music therapy is the opportunity for choices. This is extremely essential in any setting, where most of the day is pre-planned for the students. Music therapy sessions are structured to offer the client choice of music, songs, and musical instruments, and in some cases, even the choice to attend or not attend sessions.

Some music therapy goals identified for adolescents with developmental challenges are:

- To decrease anxiety and agitation

- To promote relaxation

- To increase socialization

- To increase cognitive and academic skills

- To promote group cohesion

- To elevate mood

- To promote self-esteem, self concept and dignity

- Todecrease disruptive behaviour

- To improve receptive and expressive communication

- To improve gait

- To improve range of motion

Music therapy is accessible and adaptable to anyone and does not focus on achieving musical skill or proficiency. We do not profess to prolong life or cure disease, but rather to promote quality of life. Music offers structure through patterns, rhythm and harmony as human beings we seek structure and organization. Our basic responses - breathing, the pace of our step, our heart beat - are all organized rhythmically in patterns. Our human response to music is basic \& innate. Music can facilitate release of tension and stimulate endorphins. There is a book recently released (2006) called "This is your Brain on Music: The science of a human obsession" by Daniel J. Levitin that is fairly easy reading - it explores 


\section{3:3 Fall 2006}

the human response to music at an in depth and analytical level for those interested in learning more about the links between human physiology and music

Chodzinski: Your career as a music therapist has provided opportunities for you to work in schools. Please explain what services you provide and how school boards or individual teachers or parents may contact you.

PringleI provide music enrichment to groups of children in elementary and secondary school classrooms. The music program is custom designed to support the needs and challenge the abilities of each group member. Groups are ideally comprised of children with similar needs; however ranges of needs can be accommodated. The ideal group size is 6 children/adolescent's supported by their Educational Assistants and the classroom teacher(s). As there are many opportunities for turn taking, larger group numbers makes "waiting" more difficult. The students in groups I currently work with have a range of abilities and diagnosis such as: non-verbal (or verbal or assisted communication), non-ambulatory, ASD, Down syndrome, verbal, anxiety disorders, Acquired Brain Injuries, and developmental delay..

The program is fairly structured by activities so that the group members can anticipate what is coming and have a sense of familiarity and comfort..

A typical session looks like:

Greeting/Hello Song

Peer Awareness Activity/Song

Instrumental (turn-taking) Tasks

a) drum improvisation

b) group instrumental song
Familiar Songs (requests if possible)

Individual instrumental improvisations (guitar, xylophone)

Movement Activity

Closing/Goodbye

Chodzinski: How might teachers use music and musical instruments in classrooms to help create a stress free learning environment?

Pringle:My work with schools thus far has been providing group programs for students with special needs. A music therapist certainly can consult with an educational team to provide resources for promoting positive educational settings and reducing stress in the classroom and the school workplace.

A music therapist could consult to address issues such as:

- Noise level / auditory distraction in the class room

- Planned use of recorded \& live music:

- Using music during breaks and transitions

- Using music at pre-planned times to increase attention

- Using \& selecting back ground music - pros \& cons

- Using "walk-mans" for indi vidual music listening to pre ferred music

- Learning relaxations tech niques and cuing in response to music

Music can be used in many creative ways to nurture a child's educational experience.

- Use music (songs, books with songs, rhythm, chant, song writing) to support and reinforce academic concepts.

- Drumming - to focus and express energy, to share a cohesive group experience, to follow a leader and have oppor- tunity to lead the group to reinforce academic concepts such as counting, patterns, or poetry! (some boards have access to drums that can be loaned out to specific classrooms through arts programs)

- With younger children many teachers interweave song throughout the daily routine for cuing and teaching through repetition. Many teachers use music circles - piano, guitar, a cappella, small rhythm instruments, and camp-fire style songs.

- To extend this in a classroom of older children - use music to reinforce learning (songwriting / rap), use instrumental recorded music during reading / quiet work times.

- Imagery activities - select music that is dramatic (i.e. film music, Romantic program music). Tell the students to imagine they are going to movie, when the music begins the curtains open and the picture begins - it can be whatever they want it to be - they are watching with their minds eye - tell them to focus on what they see and feel while watching their movie. When the music stops they can open their eyes and discuss or draw / paint what they experienced

Chodzinski: What types of music would you suggest a teacher use in school classrooms and with what age groups?

Pringle:I am a strong advocate of using the music that is preferred by "the client." Therefore the music that is selected to motivate school classrooms would be the music that children are engaged by and respond to - this will correspond directly with their development. Children should have 
opportunities to "bring in" their music - recorded or live - to share and express this important part of their selves with their peers and teachers.

I believe that children of all ages should be exposed to a wide range of music and styles - world music (very broad suggestions: Spanish, Indian, East Asian, African, Reggae, Cuban, Soca...) is a wonderful resource that can open the ears of all children. The Romantic period provides a wealth of "program music" music that was composed to elicit imagery and a sense of adventure one only need look to the works of Bedrich Smetana, Mussorgsky, Rimsky-Korsakov, Tchaikovsky and Chopin. Popular music throughout the $20^{\text {th }}$ century right up to today will continue to extend their "pallet" for example 40 's Big Band music, Musical Theatre / Broadway hits, Dance music from the ' 50 s, Elvis, the Beatles, rock, country and hip hop all bring to the ear a magic that is unique to the individual.

Music that promotes a relaxation response, which can be useful in decreasing stress can be somewhat prescriptive.

Musical choices for creating a soothing, relaxation response:

- Instrumental music (lyrics can be distracting)

- $60-85$ beats per minute (closest to resting heart rate)

- no dramatic changes in volume, pitch or timbre

- choose instrumentation carefully (high flute, violin, vocals can increase stress)

Examples:

Baroque music: Bach, Pachabel, Vivaldi

Solitudes (often accompanied by nature sounds, depends on personal taste)

New Age music (Enya, Steven Halpern)

\section{River Ash by Kelly Walker}

Chodzinski: What can school administrators do to encourage and support the use of music therapists in schools and also to promote the use of music as a strategy to relieve stress in schools?

Pringle: What comes to mind is a variety of specific proactive interventions that administrators could implement. These might include:

Revisit policies that deal with using "therapists" in school settings.

Consider hiring music therapists as consultants to provide programming guidelines.

Invite music therapists to present workshops and professional development for teachers.

Increase the emphasis on music in classroom curricula and in school activities.

Provide schools with adequate budgets to purchase music resources, enhanced technology and of course encourage teachers and students to listen to music as part of a daily stress reduction program.

Use resources that are already available to implement programs such as arts consultants with the board and music educators.

Allow fundraising by parent and student groups to support programs that are considered "extras"

The following are real case examples where music has made an extraordinary difference in the life of an adolescent.
Example One:

Dave is a 17 -year-old student with an acquired brain injury. $\mathrm{He}$ is referred to music therapy to explore his post-injury cognitive skills and emotional issues, as well as to work on regaining some degree of mobility and range of motion in his left hand. Dave is a poet at heart. It is a natural progression for therapist and client to explore song writing. His first composition focuses on looking forward, not back, and focusing on the good things life has to offer. He is intensely aware of his losses, but also acutely aware of his daily successes. To improve fine-motor skills, the music therapist introduces the piano keyboard. Dave is motivated to use his left hand. He begins playing by playing one note, and now progresses to three note chords. Dave indicates that for his next composition he wants to write a tribute to all those individuals who helped him come back from his injury. Later, Dave and the music therapist are invited to perform his composition "The Might Survivor" for an audience of 200 at an event celebrating personal success stories. Dave plays the introduction on the piano and sings all 3 verses from memory. It is 2 years to the day since his accident.

\section{Example Two:}

Lisa is a 15-year-old adolescent with Down Syndrome. Her mother contacts a music therapist to improve Lisa's expressive communication skills. Lisa communicates through proficient signing, vocal squawking and loud grunts. She experiences behavioural outbursts at social functions. The music therapist senses that although Lisa is able to talk, she dislikes the sound of her own voice. Together, they explore the use of the voice in different ranges and at varying tempos. A "Blues" melody is written for Lisa 
to practise using her voice. Lyrics are comprised of one-syllable sounds such as "La" or "Ba", or "Do". Lisa loves the exercise and begins to use her new voice in other environments. At a leisure night with other teens, for the first time, instead of acting out, she participates in a discussion about favourite foods. Her teachers at school note a difference in her disposition. She orders a meal coherently and confidently at a restaurant. And, in one unforgettable moment, Lisa greets her father early one day at the breakfast table with "Good Morning Dad!" It is the first time her father has heard her say those words.

\section{Example Three:}

Two teens with autism, Tom and Adam are placed together in a music therapy group. It does not go well initially. Both boys engage in self-stimulative behaviour, appearing not to notice the therapist or each other. The music therapist sings to both boys, frequently using their names. Instruments are strategically placed around the room and in close proximity to each boy. A large gathering drum is in the centre of the room. After a few weeks of therapy, eye contact between the boys is observed. One day, the therapist begins to beat a repetitive rhythm on the drum. It matches the tempos of the boys rocking and swaying. She softly begins to sings "Welcome to Tom, Welcome to Adam, Welcome to the Music world" maintaining the same, steady rhythm on the drum. Slowly and with caution, Tom edges towards the drum, transfixed by the sound. Adam remains at the other side of the room, but he is watching and listening. Tom tentatively touches the drum, sniffs it and looks underneath it. Adam begins to vocalize quietly. The two boys are united in one cause - making music together. From that session on, the group solidifies and develops. New songs are improvised. Adam demonstrates a gift for harmonizing melodies. Tom explores complex and syncopated rhythms on the drum. The boys eventually trust each other and the therapist enough to play together on a large xylophone. The music world that they created and nurtured is safe and non-threatening.

For more specific information on music therapy:

www.musictherapy.ca (CAMT website) www.mtao.org (MTAO website) www.soulsongmt.com

For more information about music therapy services contact Adrienne Pringle, MMT, MTA

Soul Song Music Therapy Burlington,

Ontario 289-259-5546

adriennepringle@hotmail.com/

apringle@cvh.on.ca

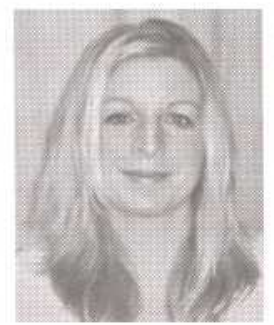

Adrienne Pringle holds a B.A. (hons) in Music and English from Mount Allison University, and a BMT (Honours Bachelor of Music Therapy) and Masters Degree in Music Therapy from Wilfrid Laurier University. She is an accredited member of (CAMT) the Canadian Association of Music Therapists and is the current Chair of Continuing Education. Her work and research interests are in the area of palliative care, long term care with older adults, children with Autism Spectrum Disorders and Down syndrome, and Developmental and Global development delays as well as individuals with Acquired brain injury. She interned with Halton Music Therapy Services. Adrienne provides services to patients at the Credit Valley Hospital, Palliative Care Unit, Mississauga, Ontario, Canada and is an adjunct faculty member at Wilfrid Laurier University where she teaches and supervises undergraduate and graduate students in Music therapy. Currently she is supervising several interns at long term care facilities in Southern Ontario. In addition she promotes her own private practice. Adrienne has been commissioned by several school boards to provide music enrichment and therapy services. Foremost is her love of singing and playing the piano and guitar not only for herself but for others. Her paper Giving Voice to Dying echoes her professional commitment. She is also available for weddings and funerals.

\section{Call for papers}

This is a call for papers, articles, books and or web site reviews, and practical applied research of interest to professionals and others interested in the critical issues and concerns selected as an issue topic by the Editorial Board of the Brock-Golden Horseshoe Educational Consortium.

The Editorial Advisory Board has approved the themes for the next two issues of Teaching and Leaming.

Winter 2007, Volume 4:1 Boys and Literacy

Spring/Summer 2007, Volume 4:2 Action Research: Student Sucesss
Submissions will be received on or before the following dates:

Volume 4:1 February 15, 2007

Volume 4:2 April 30, 2007

Submissions should be sent to Dr. R. Chodzinski, editor, Teaching and Learning. c/o Nancy Schoeberle, Administrative Assistant, Brock University, Hamilton Campus, 1842 King Street East Hamilton, Ontario, L8K 1V7 email Nancy.Schoeberle@brocku.ca. All manuscripts must be proof read, limited to 2500-3000 words in Microsoft Word Format. All references must checked and accurate. Quotes or other printable material that require authority to reprint must be approved before an article is submitted. 